\title{
Factors affecting adult body condition in the endangered northern rockhopper penguin
}

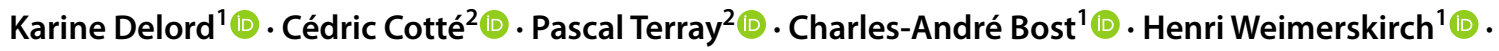 \\ Christophe Barbraud ${ }^{1}$ (D)
}

Received: 30 April 2020 / Accepted: 15 January 2021

(c) The Author(s), under exclusive licence to Springer-Verlag GmbH, DE part of Springer Nature 2021

\begin{abstract}
Understanding the factors that drive the dynamics of populations of long-lived species presents a unique challenge for conservation management. Here, we investigated long-term change in the body condition of adult northern rockhopper penguins Eudyptes moseleyi at Amsterdam Island, southern Indian Ocean, which hosts 5-10\% of the global population of this endangered species. Analysis of a long-term dataset (1994-2016), concurrent to the population's rapid decline, revealed no trend in adult northern rockhopper penguin body condition over time at the stages considered in this study, i.e. breeding and moulting. However, body condition varied between years and sexes and part of this variation was explained by environmental factors. Males were on average in better condition than females whatever the stage and individuals on average were in better condition during the moulting compared to the breeding period. The environmental conditions [sea surface temperature anomaly (SSTa), Subtropical Indian Ocean Dipole (SIOD) and Southern Annular Mode (SAM)] appeared to impact non-linearly the body condition. Overall, females were in better condition for negative values of SAM, SIOD and SSTa. The body condition of males exhibited similar but less complex and more significant patterns, with decreasing body condition for increasing SAM, SIOD and SSTa. The absence of long-term trends in male and female body condition suggests that the very low reproductive output and declining population since 1997 is probably not the result of environmental conditions during pre-breeding and pre-moult and necessitates further research into possible drivers during the breeding season.
\end{abstract}

\section{Introduction}

Understanding the factors that drive changes in wildlife populations is central to population ecology and conservation biology, being the first step permitting robust prediction of population trends. In a context of global warming, the marine environment has changed during recent decades and climate scenarios predict changes to continue (Parmesan and Yohe 2003; Cabré et al. 2015). As a consequence, processes

Responsible Editor: T. A. Clay.

Reviewed by N. Dehnhard and an undisclosed expert.

Karine Delord

karine.delord@cebc.cnrs.fr

1 Centre D'Études Biologiques de Chizé, UMR 7372 du, CNRS-La Rochelle Université, 79360 Villiers-en-Bois, France

2 LOCEAN Laboratory, Sorbonne Universités (UPMC, University Paris 06), CNRS-IRD-MNHN, 4 Place Jussieu, 75005 Paris, France controlling primary productivity are affected resulting in modification of food availability in some marine ecosystems (Moline et al. 2004). Food resources are known to affect body mass of individuals with potential effect on reproductive investment and/or survival (Boutin and Larsen 1993; Kitaysky et al. 1999; Oro and Furness 2002; Altmann and Alberts 2005). In response, morphological traits of animals (i.e., body mass of consumers / higher trophic level predators) were found to be partly sensitive to global warming (Weimerskirch et al. 2012) as well as phenological traits, i.e. timing of biological events, such as reproduction or migration (Radchuk et al. 2019).

As diving and flightless seabirds, penguins are particularly sensitive to oceanographic changes and have been identified as marine sentinels of ecosystems (Boersma 2008; Bost et al. 2015; Iles et al. 2020). Penguins are important top consumers in the Southern Ocean food web and the Southern Ocean hosts more than $90 \%$ of all penguins (Croxall and Lishman 1987; Guinet et al. 1996). Penguins (Spheniscidae) are also amongst the three most threatened groups of seabirds, with 10 of 18 species classified as Endangered or 
Vulnerable (Dias et al. 2019). Eudyptes are the largest genus by number of species, and are amongst the most threatened with six of seven species being globally threatened (Borboroglu and Boersma 2013; BirdLife International 2018). Most Eudyptes penguin species are endangered exhibiting recent dramatic population decline mainly due to climateinduced reduction in prey availability or quality, causing nutritional stress and low demographic rates (BirdLife International 2018; Crawford et al. 2009; Hiscock and Chilvers 2014; Trathan et al. 2015; Morrison et al. 2015; Barbraud et al. 2020). Among the major current threats identified for Eudyptes penguins are climate change (increasing sea surface temperature, wind regime changes or extreme weather conditions) and environmental variability often resulting in shifts in marine food webs (Guinard et al. 1998; Barlow et al. 2002; Hilton et al. 2006; Dehnhard et al. 2013a, b; Horswill et al. 2014; Demongin et al. 2010; Wolfaardt et al. 2012), although the availability of resources exploited by fisheries and the increase in predation pressure (i.e., by giant petrels Macronectes spp. and fur seals Arctocephalus spp.) may play a role in some sites (Cuthbert et al. 2009; Morrison et al. 2015). Other factors, such as diseases, could also be implicated in population declines (De Lisle et al. 1990; Cooper et al. 2009; Horswill et al. 2014; Jaeger et al. 2018).

The global population of northern rockhopper penguins (Eudyptes moseleyi, Mathews and Iredale, 1921), an endangered species breeding on seven remote islands in the temperate South Atlantic and southern Indian oceans, experienced severe declines during recent decades $(57 \%$ over the past 37 years; Cuthbert et al. 2009; Birdlife International 2018; Barbraud et al. 2020). The population of northern rockhopper penguins breeding at Amsterdam Island (37 $50^{\prime}$ S; 77³' E), southern Indian Ocean, has been declining at an average rate of 3-4\% per year since the early 1970 s (Guinard et al. 1998; Barbraud et al. 2020) in line with a significant decline of the breeding success since 1997 (Fig. 1, Jaeger et al. 2018). In this study, we focus on the Amsterdam Island population only. Northern rockhopper penguins are exposed to epizooties, namely to the erysipelas diseases (Erysipelothrix rhusiopathiae) and potentially to avian cholera (Pasteurella multocida), and although it has been hypothesized that this may be one of the causes believed to be responsible for the population decline, their impact remains unknown (Jaeger et al. 2018).

Eudyptes penguins body mass and phenology are sensitive to climate conditions, i.e. increasing or changing ocean temperatures may reduce nutrients/productivity and ultimately alter food availability, which in turn has been shown to be a known driver of body mass and reproductive success (Dehnhard et al. 2015a, b). Low body mass or body condition in penguins generally negatively affects reproductive success (Robinson et al. 2005; Crawford et al. 2006, 2008). Indeed, Eudyptes penguins

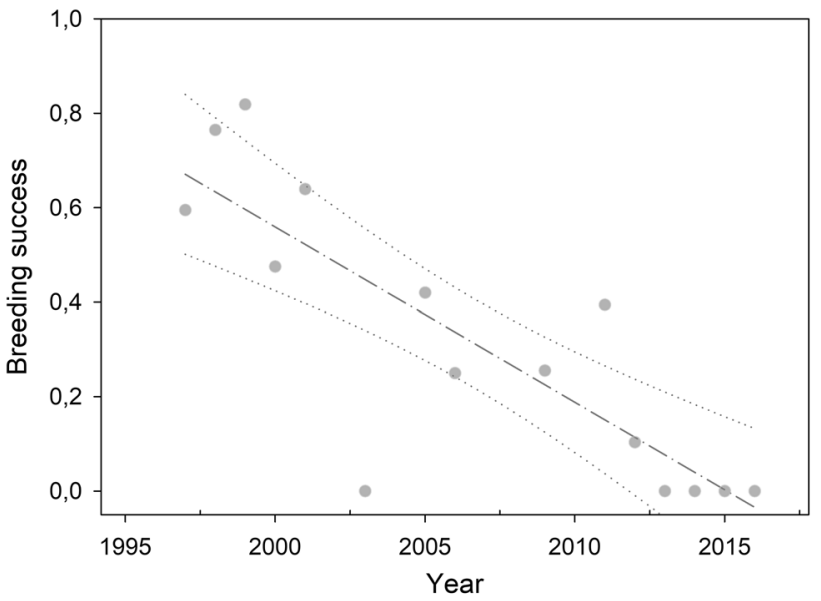

Fig. 1 Breeding success of adult northern rockhopper penguin on Amsterdam Island from 1997 to 2016. Linear regression (dash-dotted line; $r_{2}=0.70$ ) with $95 \%$ confidence intervals (dotted lines) are shown

exhibit an extremely long courtship-incubation fast (35-49 days) with males assuming an incubation/guard fast of 31-40 days (Williams 1995). Both sexes were found to alter their provisioning and foraging efforts in relation to poor food conditions, with males provisioning less food to their chicks during the crèche stage than females (Morrison et al. 2016).

One ecological hypothesis (food resources hypothesis) to explain the dramatic decline of the northern rockhopper penguin could be modification of food resources at sea (through reduction or displacement of prey) encountered by the birds throughout their annual cycle, as a result of environmental changes. Since northern rockhopper penguins mainly feed on low trophic level prey (euphausiid Thysanoessa gregaria, small fish and juvenile squid (Tremblay and Cherel 2003)), this makes them potentially sensitive to changes in oceanographic conditions that affect primary productivity within their foraging range. Furthermore, penguins are capital breeders, i.e. organisms that accumulate energy reserves for breeding before reproductive events (Cherel et al. 1988a; Meijer and Drent 1999). Consequently the birds need to acquire the necessary body reserves for reproduction before the breeding period, but also before the moulting period, which is particularly energy-demanding in penguins due to a prolonged fasting period during a catastrophic moult (Cherel et al. 1988b; Adams and Brown 1990). For southern rockhopper penguins $E$. chrysocome, it has been suggested that the pre-post-moult period could be critical for adult survival, the environmental conditions during this period being correlated with adult survival (Dehnhard et al. 2013a, b).

Based on this knowledge and under the hypothesis that declines in breeding success and abundance of northern rockhopper penguins at Amsterdam Island are caused by a changing of food resources at sea, we used data from a 
23-year (1994-2016) study of northern rockhopper penguins at Amsterdam Island to estimate male and female adult body condition at two key stages of their annual cycle (the onset of breeding and moulting) to test this hypothesis. Using this dataset, we addressed the following questions: (1) does male and female body condition show a temporal trend? (2) are male and female body condition and breeding success affected by climatic factors? We predicted a relationship between body condition, breeding success and climate factors known to affect primary productivity in the species' foraging areas.

\section{Materials and methods}

\section{Study area and species}

Northern rockhopper penguins were studied at Amsterdam Island $\left(37^{\circ} 50^{\prime} \mathrm{S} ; 77^{\circ} 33^{\prime} \mathrm{E}\right)$ in the southern Indian Ocean, located just north of the SubTropical Front (STF; Graham and De Boer 2013). The entire population of Amsterdam Island (12, 000 breeding pairs representing $5-10 \%$ of global population and $62 \%$ of the Indian Ocean population; BirdLife International 2018; Barbraud et al. 2020) breeds in several and separate sub-colonies in the area of the Entrecasteaux cliffs (Jaeger et al. 2018). Males arrive at the breeding colonies during the second half of July and females during the first half of August (Duroselle and Tollu 1977; Tollu 1978; Thiebot et al. 2014b). After laying in early September, both parents incubate the two eggs alternately until hatching. Incubation is generally divided in three shifts, the first shared between males and females, the second by female and the third by male. Incubation lasts 33-39 days. Hatching takes place in October. Only males are guarding the chick, which leads to a prolonged fasting period after incubation (17-26 days; Williams 1995). At best, only one chick per pair reaches the crèche stage, when both parents forage simultaneously and leave their chick unguarded in October-November. The chicks fledge in late December, about 60-70 days after hatching. Then both adults depart on their pre-moult trip for 3 to 4 weeks (up to 8 weeks) and return to the breeding colony in March for a prolonged fasting period to moult.

Northern rockhopper penguins are opportunistic foragers, hunting in different areas during the breeding and non-breeding seasons. The foraging range of northern rockhopper penguins has been investigated during the breeding period on Amsterdam Island (Heerah et al. 2019; C. A. Bost, unpublished data) and during the non-breeding period (Thiebot et al. 2012). Incubating penguins perform looping trips, with a mean foraging range of $230 \mathrm{~km}$ south of Amsterdam, although some breeders may forage as far as $410 \mathrm{~km}$ off their colony. Brooding birds usually forage much closer to the colony, staying within the region of the shelf $(8-80 \mathrm{~km}$; C. A Bost, unpublished data). Tracking data further revealed that birds disperse after moult over an area stretching to the East of Amsterdam (approx. $47^{\circ} \mathrm{S}$ and $110^{\circ} \mathrm{E}$ ), performing longrange movements of up to $2200 \mathrm{~km}$ away from the colony, without any return to land (Thiebot et al. 2012). The majority of birds head South-east, along the Indian Ridge and forage south of the southern boundary of the SubTropical Front using deep waters (3000-3500 m) with very heterogeneous sea surface temperature anomalies and chlorophyll concentrations (Thiebot et al. 2012).

Northern rockhopper penguins are relying mainly on pelagic crustaceans, in particular euphausiids (Cherel et al. 1999) and juvenile squid at Amsterdam Island (Tremblay and Cherel 2003). Dietary studies from Amsterdam Island show seasonal changes in diet with crustaceans and cephalopods, respectively, dominating the diet during the early crèche stage, while fish being the main prey item in the later stages of chick-rearing (Tremblay et al. 1997; Tremblay and Cherel 2003). Isotopic values of blood collected at the arrival in the colony in spring indicate that adult birds also forage in subtropical waters in late winter (Thiebot et al. 2012).

\section{Biometry and breeding success}

Body size measurements (culmen length $( \pm 0.1 \mathrm{~mm})$ using calipers, and body mass $( \pm 50 \mathrm{~g})$ using a Pesola ${ }^{\circledR}$ spring balance) were obtained annually since 1994 on a sample of adults ( $263 \pm 37$ individuals each year) captured on arrival at their colony at two key phases of their annual cycle. First, on arrival at the colony at the onset of the breeding season (July-August; hereafter named breeding), when individuals return from their non-breeding grounds. Second, after their pre-moult trip (hereafter named moulting) between 8 and 20 February, when they return to the colony to moult following the breeding period. Individuals were sexed according to their arrival date at the colony after winter migration (males 20 July-3 August; females 10-26 August). The frequency distribution of the culmen length of sexed birds was then used to determine a culmen length threshold used to sex individuals captured during the moulting period when both sexes arrive together (Warham 1970; Steinfurth et al. 2019). Since there is a slight overlap between male and female culmen length, we removed individuals belonging to the 90th percentile of the culmen length frequency distribution for females and the 15 th percentile for males to remove potential sexing errors. This resulted in removing $15.4 \%$ and $14.5 \%$ of females and males, respectively. A threshold value of $46 \mathrm{~mm}$ was used to sex individuals captured during the moulting period (males $\geq 46 \mathrm{~mm}$, females $<46 \mathrm{~mm}$ ). Since our sexing method excluded the smaller males and the larger females, it may have biased our results. We thus conducted a sensitivity 
analysis by creating another dataset where the 15\% largest males and the $15 \%$ smallest females were removed and reran the analyses.

Breeding success was calculated since 1997 on a sample of 14-170 nests depending on the year, as the ratio between the number of chicks counted in December just before their departure at sea and the number of incubating adults (i.e. number of breeding pairs) counted in the first half of September to coincide with the peak egg laying.

\section{Environmental variables}

Three environmental covariates were considered to explain inter-annual variations in body condition. The local sea surface temperature anomaly (SSTa) and two climate indices: the Subtropical Indian Ocean Dipole (SIOD) and the Southern Annular Mode (SAM), which are major modes of climate variability in the southern Indian Ocean (Behera and Yamagata 2001; Hall and Visbeck 2002; Hermes and Reason 2005; Terray 2011). As detailed below, these three environmental covariates were chosen as they likely characterize the marine environment used by the penguins at the times of interest from the local, regional and global scales, respectively (Thiebot et al. 2012).

We considered two periods for the climate indices: (i) between the end of the breeding period and the beginning of the moulting period (pre-moult; December of year $t-1$ to January of year $t$ ) to test for an effect of climate conditions on body condition prior to moulting, (ii) between the end of the moulting period and the beginning of the following breeding period (pre-breeding; March to July of year $t$ ) to test for effects of climate conditions on body condition prior to the breeding period and on breeding success.

Sea surface temperature (SST) plays a fundamental role in net primary production (Behrenfeld et al. 2006), which may have an effect on the distribution and abundance of northern rockhopper preys. SST is known to affect body condition and demographic parameters in several seabird and penguins species (Le Bohec et al. 2008; Barbraud et al. 2012; Dehnhard et al. 2013b; Horswill et al. 2014; Bost et al. 2015). SSTa is regulated by different climate processes/modes operating at different spatial scales (e.g. local, regional and global scales).

Monthly in situ SSTa data were obtained from https:// iridl.ldeo.columbia.edu/SOURCES/.NOAA/.NCEP/.EMC/. CMB/.GLOBAL/.Reyn_SmithOIv2/.monthly/.ssta/. To take into account the variation in the spatio-temporal distribution of adult northern rockhopper penguins, SSTa was extracted during the pre-moult (from December of year $t-1$ to January of year t) for the sector $37^{\circ}-44^{\circ} \mathrm{S}, 75^{\circ}-82^{\circ} \mathrm{E}$, and during the pre-breeding (wintering from March to July of year $t$ ) for the sector $37^{\circ}-40^{\circ} \mathrm{S}, 75^{\circ}-90^{\circ} \mathrm{E}$ when birds use a larger foraging area (Thiebot et al. 2012; Heerah et al. 2019). Finally, SSTa during the incubating period (September) was extracted for a restricted area $35^{\circ}-40^{\circ} \mathrm{S}, 75^{\circ}-80^{\circ} \mathrm{E}$ (Heerah et al. 2019) to test for effects of climate conditions on breeding success.

The SIOD is defined as the leading mode of the SST variability (i.e., a time series) in the domain $30^{\circ} \mathrm{E}-150^{\circ} \mathrm{E}$ and $10^{\circ} \mathrm{S}-50^{\circ} \mathrm{S}$ (Behera and Yamagata 2001; Terray 2011). This index is standardized (e.g. mean and standard deviation equals to 0 and 1 , respectively) and positive values of the index (e.g. positive SIOD events) correspond to positive and negative SSTa, respectively, in the southwest and northeast of the southern Indian Ocean basin. This SSTa pattern is linked to a strengthening of the Mascarene high (e.g., a zone of high Sea Level Pressure near Mascarene Island), which corresponds to a blocking atmospheric situation and an undulation of the westerly mean flow with more southeasterly (northwesterly) wind anomalies eastward (westward) of Amsterdam Island. This implies increased (decreased) wind speed eastward (westward) of Amsterdam Island. Note that Amsterdam Island is located exactly at the zero point of the SSTa gradient between the two poles of the SIOD on average. In other words, the in situ SSTa and SIOD bring complementary information on the climate conditions, which may impact northern rockhopper penguins. Consequently, SIOD was used in the analyses during both pre-moult and pre-breeding periods as it may affect northern rockhopper penguins indirectly through its effect on SST and thermocline regional anomalous patterns in addition to in situ SST and thermocline anomalies. It has been shown to affect the foraging behaviour and population dynamics of king penguins Aptenodytes patagonicus breeding at Crozet islands (Bost et al. 2015).

Finally, SAM is a global large-scale climatic index defined as the difference in the normalized monthly zonal mean sea level pressure between $40^{\circ} \mathrm{S}$ and $65^{\circ} \mathrm{S}$ (Gong and Wang 1999). Monthly SAM values were obtained from the online database of the Koninklijk Nederlands Meteorologisch Instituut https://climexp.knmi.nl/selectindex.cgi.

SAM index measures the surface pressure gradient (e.g. the "see-saw" of atmospheric mass) between the middle (around $30^{\circ} \mathrm{S}-50^{\circ} \mathrm{S}$ ) and high (around $50^{\circ} \mathrm{S}-70^{\circ} \mathrm{S}$ ) latitudes of the southern hemisphere (Marshall 2003). It is the dominant mode of atmospheric variability in the southern hemisphere (Hall and Visbeck 2002). Positive values of the SAM index correspond in most cases to stronger westerlies over the high latitudes $\left(50^{\circ} \mathrm{S}-70^{\circ} \mathrm{S}\right)$ and weaker westerlies at mid-latitudes. The reverse is true for negative values. As the SAM is a large-scale and low-frequency (e.g., month to month or inter-annual variations) index, it does not correspond necessarily to the in situ wind conditions (direction and speed) in the southern Indian Ocean. As such, its link with the local SST or SIOD is complex. In other words, it is not a redundant climate variable of in situ SSTa/wind conditions or the SIOD. However, SAM may affect northern 
rockhopper penguins indirectly through its effect on westerly winds and Ekman transport (i.e., the $90^{\circ}$ net transport of the surface layer of a fluid by wind forcing) affecting upwelling intensity and mixed layer depth, and consequently biological productivity and prey availability in the STF zone (Thompson et al. 2011).

In a nutshell, local SSTa, SIOD and SAM provide different details of the background climate conditions from the local, regional and global scales, respectively, and the relations between local SST and wind with both SAM and SIOD are not direct.

We tested for a temporal trend in environmental variables using a generalised linear model (GLM) with a Gaussian family distribution and identity link function. Year was fitted as a continuous variable. The GLM model was fitted using the $\mathrm{R}$ package lme 4 .

To assess the robustness of association between the body condition of penguins and the physical environment, we also computed correlation maps between body condition of males and females during the breeding and moulting periods and the SST time series over the Indian Ocean for the two seasons preceding: the pre-breeding and pre-moult periods. Such correlation maps are standard statistical tools of climate analysis (see Von Storch and Zwiers 1999 for illustration) and they have been very useful in this science to discover new phenomena or modes of climate variability. In our context, although we extracted some environmental variables from the distribution areas of penguins during different periods of their life cycle, which we then used as explanatory variables for body condition, correlation maps are complementary to this analysis by focusing on larger spatial scales and shed light on the spatial structure of climate anomalies, which may be associated with changes in body condition.

\section{Modelling body condition}

To estimate body condition, we used the scale mass index (SMI) as recommended by Peig and Green (2009). The SMI (hereafter referred to as body condition) was calculated for each individual $i$ according to the formula:

$\mathrm{SMI}_{\mathrm{i}}=M_{\mathrm{i}} *\left(x / L_{\mathrm{i}}\right)^{\mathrm{b}}$

where $\mathrm{M}_{\mathrm{i}}$ and $\mathrm{L}_{\mathrm{i}}$ are, respectively, the body mass and the bill length of the individual $\mathrm{i}, \mathrm{x}$ is mean of bill length (47.22 $\mathrm{mm}$ for females and males pooled) and $b$ is the value of the slope estimate of a standard major axis regression (SMA) of bill length and body mass ( 0.532 for females and males pooled). The SMA between bill length and body mass was fitted using the R package lmodel 2 .

First, we tested for the effects of sex, day of the year, year, stage (breeding, moulting) and the interaction between sex and stage on body condition using a GLM with a Gaussian family distribution and identity link function. Year was fitted as a categorical effect to test for interannual variations in body condition, and day of the year as a continuous variable. To test for a trend in body condition, year was fitted as a continuous variable. The GLM model was fitted using the R package lme4.

As we suspected strong non-linear effects of climate covariates on body condition, their effects were tested using generalised additive models (GAM) with a Gaussian family and identify link function. The advantage of GAMs is the smoothing function which enables to model non-linear relationships between the response variable and the predictors (Wood 2004, 2017). Because sex and stage effects were found on body condition using GLM (see "Results") and due to potentially complex non-linear interactions between sex, stage and environmental covariates, separate GAM were developed for males and females and for each stage. Models included day of the year, SSTa, SIOD and SAM as fixed factors modelled with non-parametric smoothing functions (Wood et al. 2017). We a priori expected non-linear effects of the date at which birds arrived at the colony and were weighed because body condition is known to be influenced by several intrinsic factors (such as age, experience, individual quality...) which may affect arrival at the colony in a complex way. We proceeded with a forward-stepwise modelling approach, by fitting one variable at a time to estimate the variance explained by each (Carneiro et al. 2016). We limited the amount of smoothing $(k)$ to 3 degrees of freedom for each spline to avoid excessive flexibility and model overfitting that would have no ecological meaning (Wood 2004). As there was a single very early date of arrival (day of the year $=23$ for 2004) during moulting, we tested the same forward-stepwise modelling approach on a dataset excluding this year (see results on Online Resource 1, Table S2 and Fig S1). The models selected were similar whatever the dataset used (see "Results" and Online Resource 1, Table S1, S2). We thus considered the original dataset.

Finally, we investigated (at the population level) whether body condition between i) the breeding and subsequent moulting period and ii) the moulting period and subsequent breeding period were correlated. We first checked for normality of the body condition using Shapiro-Wilk tests and then performed correlation tests (accordingly Spearman rank correlation test (Shapiro-Wilk test; $P<0.05$ ) for i), and Pearson's test (Shapiro-Wilk test; $P>0.05$ ) for ii)).

\section{Modelling breeding success}

The effects of climate covariates and body condition on breeding success were tested using GAM with a Gaussian 
family and identify link function. Models included body condition of females and males during breeding, SSTa and SAM during the winter preceding the breeding event, and SSTa during the incubating period as fixed factors modelled with non-parametric smoothing functions (Wood et al. 2017).

Prior to GAM analysis (body condition and breeding), we used the variance inflation factor to assess collinearity between climate variables and removed covariates for which GVIF > 2 (Zuur et al. 2009). Residual normality was visually verified. The starting models included all the main effects. The best candidate model (i.e. the model containing the most informative set of covariates) was selected based on the Akaike's information criterion (AIC). A difference of more than 2 AIC units was taken to indicate strong support for the model with the lower AIC (Burnham and Anderson 2002). The GAM models were fitted using the $R$ package $m g c v$ and MASS. Data were analysed using R 3.4.1 (Team RC 2019).

\section{Results}

\section{Adult body condition}

There was a high inter-annual variability in body condition of male and female northern rockhopper penguins for both sexes and stages over the study period 1994-2016 (Fig. 2). A similarly high variability was observed for body mass whatever the sexes and the stages considered (Fig. S2). However, no long-term temporal trend was detected for the body condition whatever the period (breeding vs. moulting) or the sex considered (Fig. 2). At the population level, no correlation was found for body condition i) between the breeding and subsequent moult period (Spearman rank correlation, $\left.r_{s}=-0.12, N=19, P=0.63\right)$, and ii) between the moult and subsequent breeding period (Pearson's correlation, $r=0.29$, $N=20, P=0.22)$. Individuals were in better condition during the moulting period compared to the breeding period, and males were on average in better condition than females (Table 1, Figs. S2, 2). Body condition also varied between sexes, stages and date of the year (see Online Resource 1, Table S1). Body condition was negatively related to day of the year, indicating that individuals arriving earlier at the colony whatever the period (breeding vs. moulting) were in better condition.

All three climate covariates (SSTa, SIOD, SAM) exhibited significant temporal trends over the study period $(P<0.001)$ except SAM during the pre-moult (for female $P=0.011$ and for male, non-significant; see Online Resource 1, Table S4-S7). SSTa and SAM tended to increase (prebreeding) while SIOD tended to decrease (pre-breeding and pre-moult). All three climate covariates and day of the year
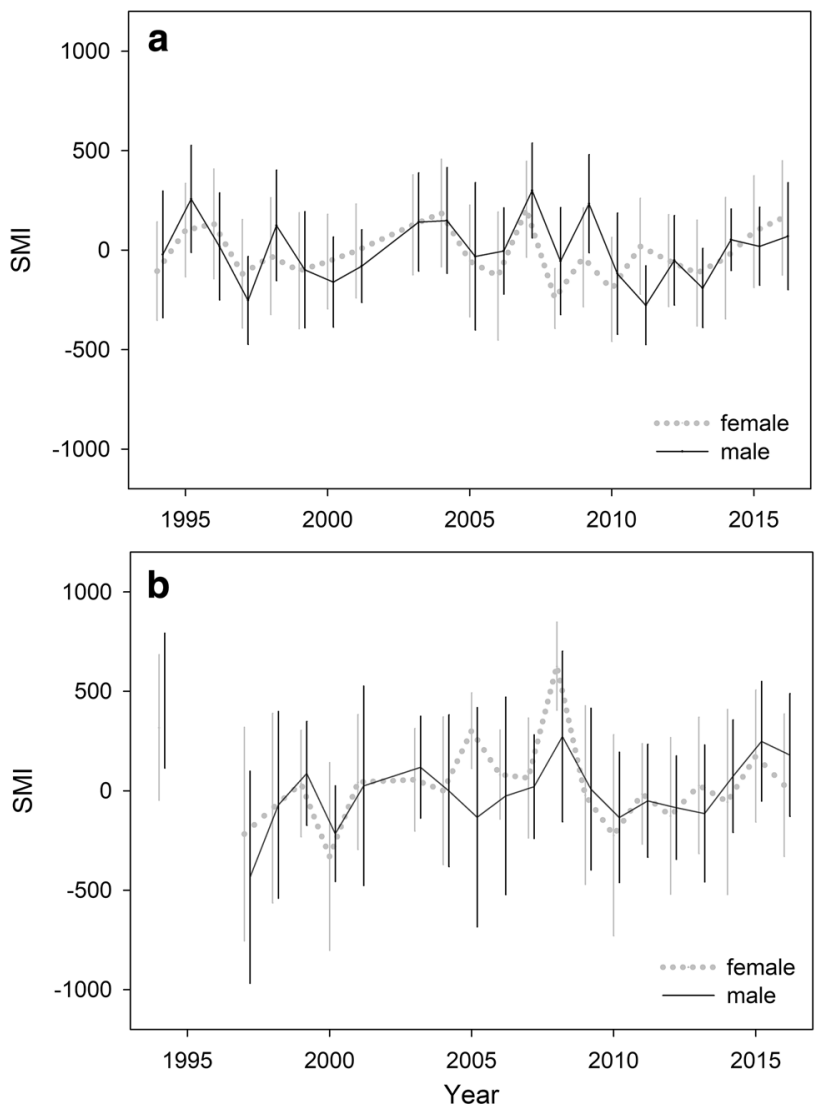

Fig. 2 Body condition (scale mass index: mean \pm standard deviation) in adult northern rockhopper penguins on Amsterdam Island from 1994 to 2016 corrected for the effect of day of the year during a breeding stage and $\mathbf{b}$ moulting stage in females (dotted grey) and males (black). To correct for the effect of day of the year we used the residuals from a GAM modelling body condition as a function of day of the year

affected male and female condition during pre-breeding and pre-moult (see Online Resource 1, Table S2). The GAM models explained $\sim 48 \%$ and $\sim 32 \%$ of the deviance during the breeding and the moulting periods, respectively. The day of the year explained a large part of the variation of body condition ( $41 \%$ and $\sim 25 \%$ of the deviance during breeding and moulting, respectively), the climate covariates explaining the remaining part ( 7\%, 2.7-11.3; see Online Resource 1, Table S2). Among covariates, SSTa (4\%) for females and SAM (12.4\%) for males better explained body condition variations during pre-breeding, while SIOD (7\% and 3.5\%, respectively, for females and males) better explained body condition variations during pre-moult.

During breeding, body condition decreased with increasing arrival date at the colony for males and females (see Online Resource 1, Tables S4-S7, Fig. 3a). These relationships were similar during the moulting period, with a clear pattern for late arriving individuals that were in lower body condition whatever the sex (Fig. 4a). 
Table 1 Average body measurements and body condition (scale mass index, body condition) for male and female northern rockhopper penguins from Amsterdam Island, southern Indian Ocean, for the 1994-2016 period

\begin{tabular}{lllllllll}
\hline Period & Sex & $N$ & Bill length $(\mathrm{mm})$ & $\begin{array}{l}\text { Bill length } \\
\text { range }(\mathrm{mm})\end{array}$ & Body mass $(\mathrm{g})$ & Body mass range $(\mathrm{g})$ & Body condition & Body condition range \\
\hline Breeding & Male & 2110 & $49.89(1.91)$ & $46.0-57.6$ & $3499.3(381.9)$ & $1850-4750$ & $3399.9(365.9)$ & $1810-4575$ \\
& Female & 1529 & $43.69(1.42)$ & $37.0-45.9$ & $3205.2(377.1)$ & $1925-4500$ & $3341.2(389.4)$ & $2012-4579$ \\
\multirow{2}{*}{ Moulting } & Male & 804 & $49.68(1.80)$ & $46.1-56.0$ & $3970.9(488.4)$ & $1700-5200$ & $3865.8(471.0)$ & $1646-5077$ \\
& Female & 572 & $43.33(1.57)$ & $37.9-45.9$ & $3631.5(463.9)$ & $1675-4800$ & $3802.4(484.1)$ & $1778-5059$ \\
\hline
\end{tabular}

Values are mean (SD)

$N$ number of individuals
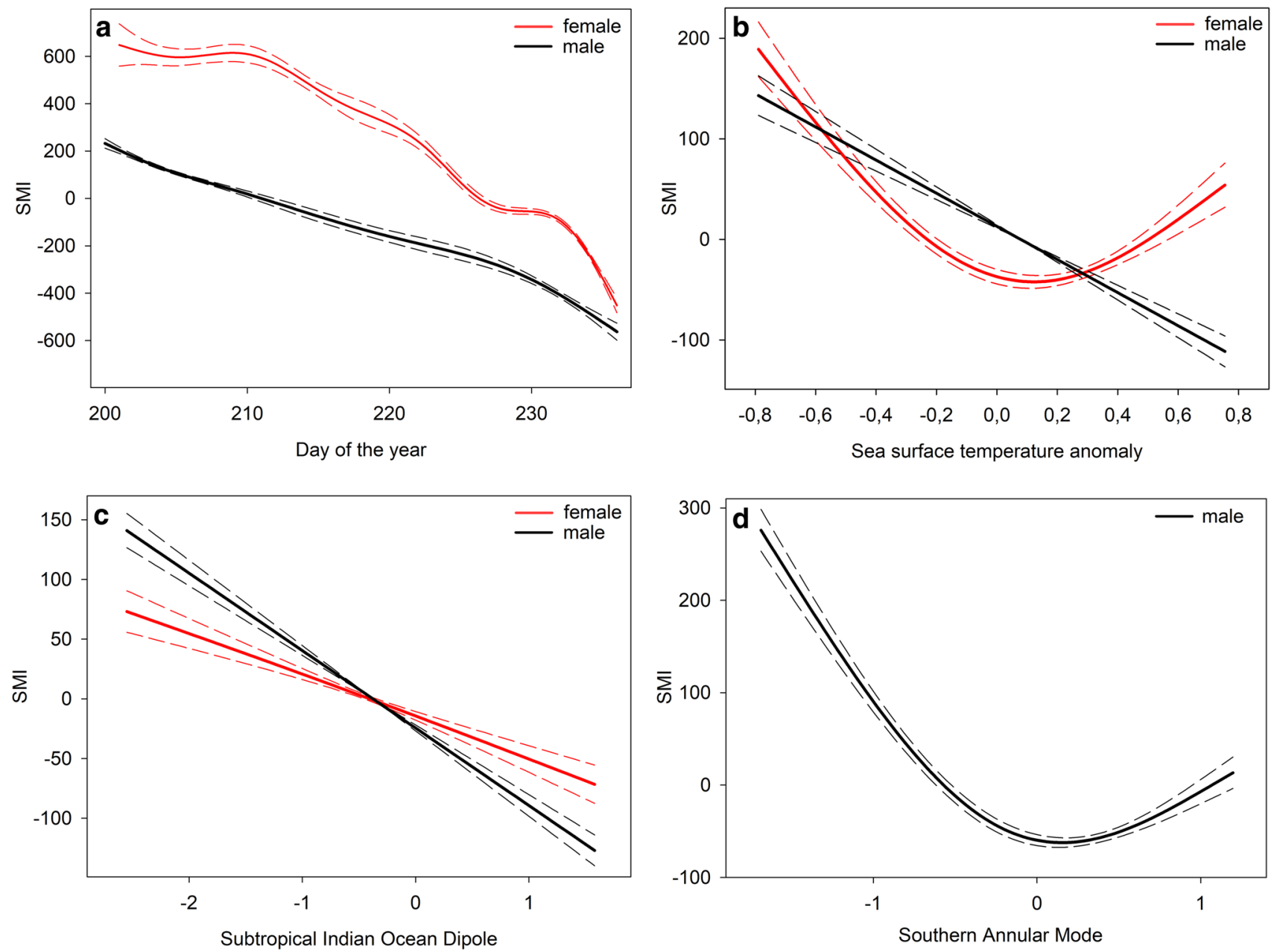

Fig. 3 Estimated smoothing curves (with s.e.) for environmental covariates during pre-breeding period in relation to the body condition of northern rockhopper penguins during the breeding stage in

females and males. Covariates considered in the model were a day of the year, b sea surface temperature anomaly, c Subtropical Indian Ocean Dipole and d Southern Annular Mode

Nonetheless, very early arriving individuals during the moulting period (days 23; Fig. 4a) had lower body condition compared to birds arriving later in late January and early February (days 27-35). These results remained robust when excluding the most extreme years (see Online Resource 1, Tables S2-S3, Figs. 4, S1).

SSTa had an effect on body condition only during the pre-breeding period (see Online Resource 1, Tables S4-S5, Fig. 3b). Male body condition decreased almost linearly 

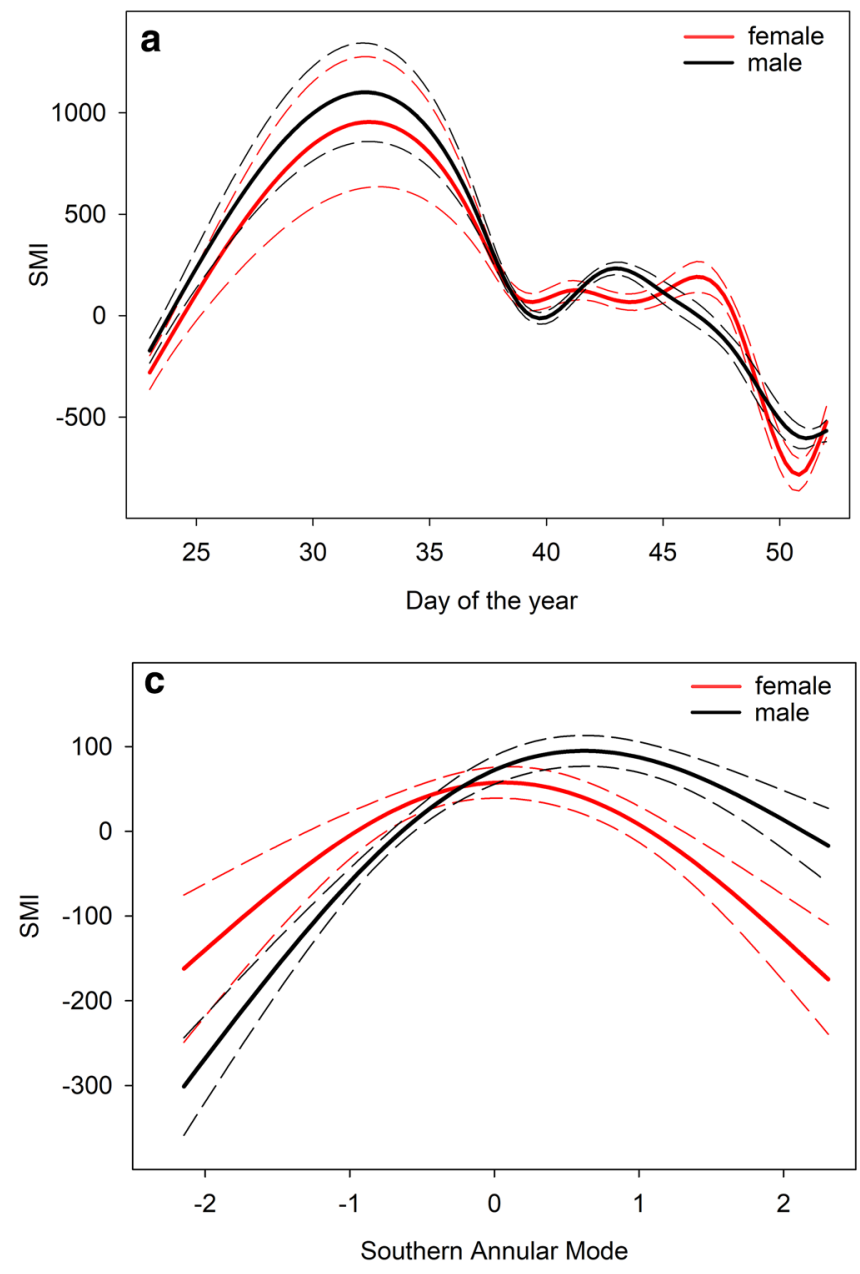

Fig. 4 Estimated smoothing curves (with s.e.) for environmental covariates during pre-moult period in relation to the body condition of northern rockhopper penguins during the moulting stage in females

with increasing SSTa. Female body condition decreased with increasing values of SSta up to null anomalies $(\sim 0)$ and then increased for warmer SSTa. Maps of correlation with Indian Ocean SST support the results obtained using the above models (Fig. 5). There were negative correlations significant at the $95 \%$ confidence level in the foraging area around Amsterdam Island during breeding, while no particular link occurred in the southeast area during pre-moult. Spatial patterns of correlation were similar for males and females, but more significant for males during the two periods (Fig. 5).

The body condition of males and females decreased with increasing SIOD during the pre-breeding period, almost linearly for both sexes (Fig. 3c). During pre-moult, body condition of males and females increased with increasing SIOD in a non-linear way (Fig. 4b).

SAM was non-linearly related to body condition in males and females whatever the period considered (see Online Resource 1, Tables S2, S5-S7, Figs. 3d, 4c) except

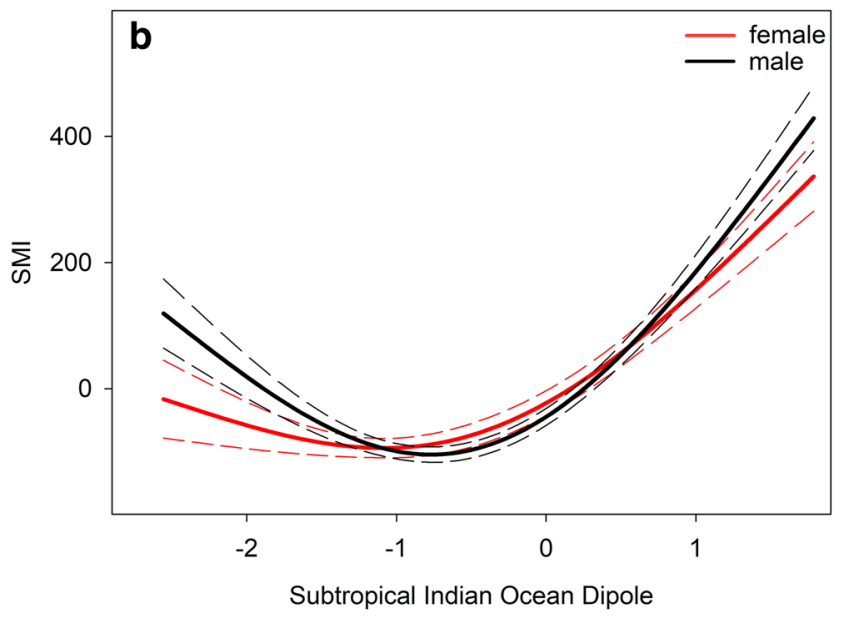

and males. Covariates considered were a day of the year, b Subtropical Indian Ocean Dipole and c Southern Annular Mode

for females during pre-breeding (the full model was not selected despite a slightly lower AIC value $\Delta=-0.71$ for the model including SAM). During the pre-breeding period, the body condition of males decreased with increasing SAM but increased for high values of SAM (Fig. 3d). Reversed relationships were observed during the pre-moult period, with values of body condition maximized for slightly positive values of SAM (Fig. 4c). Our sensitivity analysis testing for an effect of the sexing method indicated that all results remained very similar when the $15 \%$ largest males and 15\% smallest females were removed from the dataset (results not shown).

\section{Breeding success}

There was a long-term temporal trend in breeding success with a continuous decline during the period 1997-2016 (Fig. 1) and extremely low values for recent years ( 0\%). Neither the body condition of females or males during the 

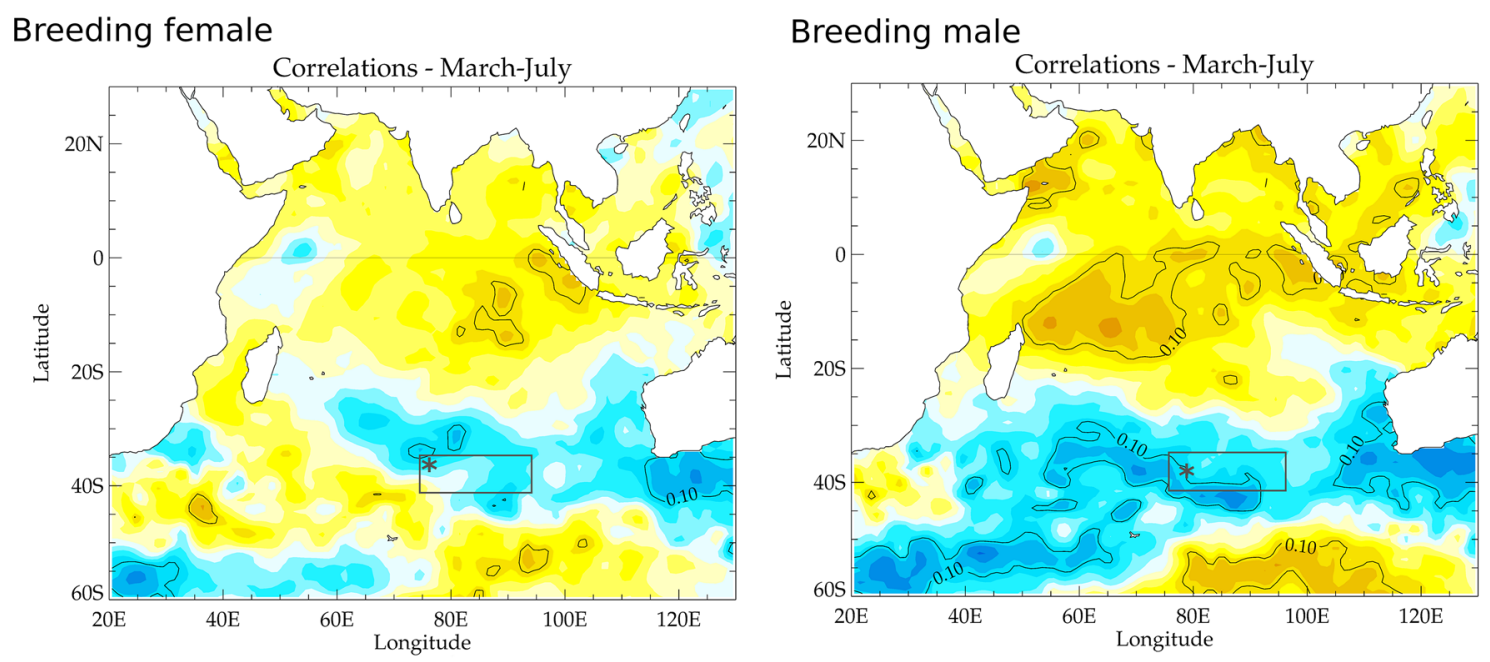

\section{Moulting female}

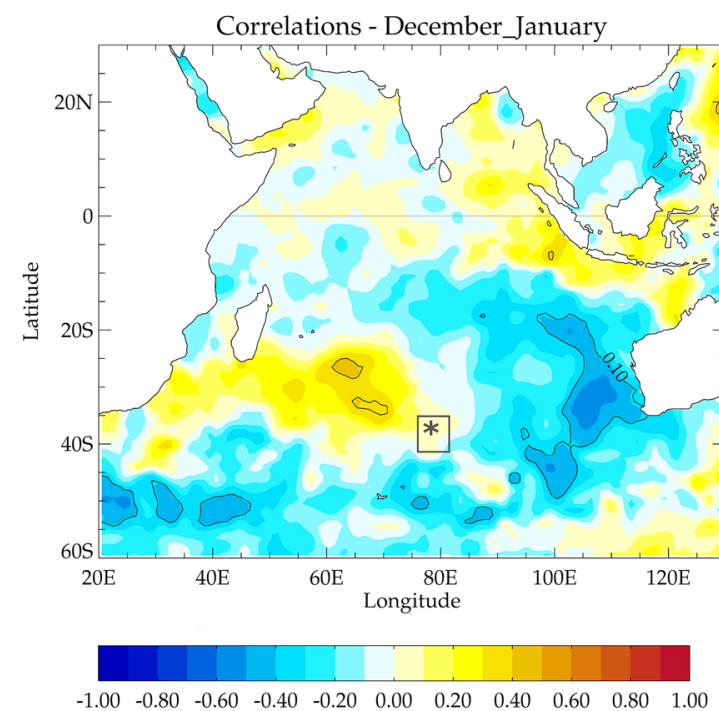

\section{Moulting male}

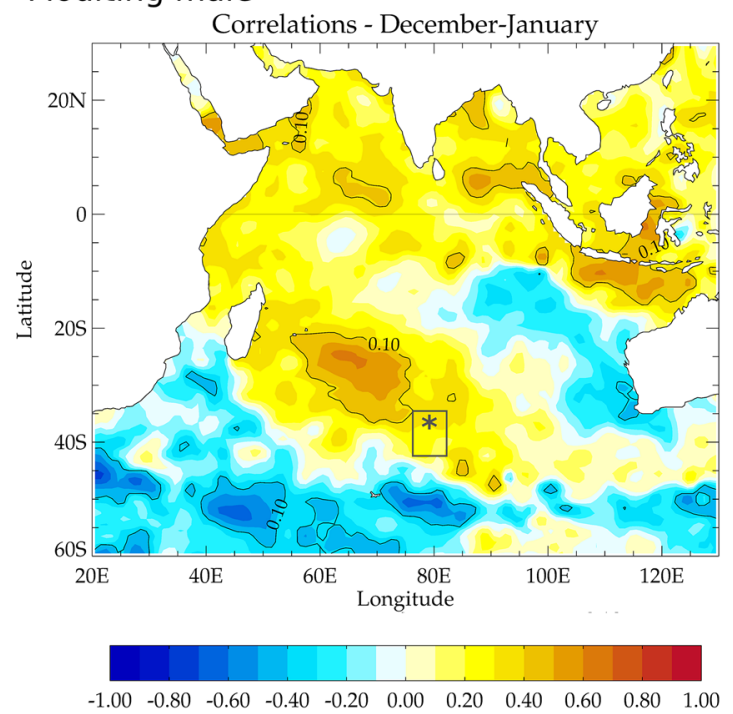

Fig. 5 Map of correlations between penguin body condition and time series of sea surface temperature according to the period (breeding stage correspond to pre-breeding austral winter period and moulting stage to pre-moult austral summer period) and sex. Amsterdam

breeding period, nor the environmental variables (SAM, SIOD and SSTa) did influence breeding success (see Online Resource 1, Table S8).

\section{Discussion}

This study examined body condition variation over a 23 -year period (1994-2016) of a threatened migratory seabird, the northern rockhopper penguin at Amsterdam Island. Contrary to the prediction of the food resources hypothesis, the body condition of males and females exhibited no long-term temporal trend, whatever the stage considered (i.e. breeding or moulting), whereas breeding success declined during the same period. Parental body condition at the start of the breeding season, and therefore food availability during the pre-breeding period, can therefore be ruled out as an explanation for the observed low breeding success in recent years. It remains open whether low breeding success in this population is explained by environmental conditions and 
food availability near Amsterdam Island during the breeding season (i.e. during the chick-rearing period, chicks starving during poor conditions not necessarily imply lower body condition of adults (Morrison et al. 2016)), disease or other factors, such as predation (Authors's unpublished data). As predicted by life-history theory, this could reflect a tradeoff between current and future reproduction (Stearns 1976). This may lead, when resources are scarce, to abandonment by adults of the current breeding episode if risks to their survival are too great (Goodman 1974; Drent and Daan 1980). Alternatively, the decline in breeding success can be due to disease (Jaeger et al. 2018) or other factors, such as predation.

\section{Sex-specific body condition}

Body condition varied between years and sexes and part of this variation was explained by the environmental factors investigated in the study. Sex-specific sensitivity to environmental variability is rather common (Badyaev 2002). Ecological theory predicts that larger animals have higher energetic demands than smaller animals, and that in times of food shortage small size confers an advantage (e.g. Wikelski and Wrege (2000)). As northern rockhopper penguins are sexually size dimorphic, with females being generally smaller than males (Warham 1970; Steinfurth et al. 2019; Cuthbert 2013), low resource availability would disproportionately affect males, which is suggested by the higher sensitivity to variability in SSTa (Figs. 4, 5). Nevertheless, males were on average in better condition than females whatever the stage. This could be linked to different parental roles. Females require additional energy reserves to produce the eggs, while males are fasting during a longer period at the colony between arrival and incubation period ( $\sim 77$ days; Williams 1995) compared to females ( 39 days), and also during moult (20-30 days, up to $\sim 60$ days of fasting). Other non-exclusive hypotheses are that these patterns in body condition could be driven by males and females using different areas prior to arriving in their colonies, or feeding on different prey, or by the time lag in arrival between males and females.

\section{Body condition and timing of arrival at colony}

The body condition of both sexes was negatively related to the day of the year, indicating that individuals arriving earlier at the colony for each of the two stages were in better condition. Timing of egg laying (which correlates with timing of arrival) and body mass were also linked with clutch mass in the closely related southern rockhopper penguin (Dehnhard et al. 2015a, b, 2016). Similarly, considering body mass at arrival (after their incubation trip), possible relationships between body mass and timing of reproduction were suggested in macaroni penguins E. chrysolophus (Horswill et al. 2016). Larger body sized females may be more likely to initiate breeding slightly earlier.

Reduced reproductive success for adults in poor body condition has been documented in Eudyptes penguins (southern rockhopper penguin; Crawford et al. 2006, 2008; macaroni penguin; Horswill et al. 2016). A carry-over effect, i.e. influence of pre-breeding stages on subsequent stages of the breeding cycle, was also evidenced from winter body mass with timing of breeding and reproductive success in penguins (macaroni penguin: Crossin et al. 2010; little penguin Eudyptula minor: Salton et al. 2015). Individuals in good body condition (i.e. breeding body mass) were more likely to breed early (little penguin: Salton et al. 2015; southern rockhopper penguin: Dehnhard et al. 2015b; Morrison et al. 2016). Nonetheless, at the population level, no correlation was evidenced here for body condition between the breeding and subsequent moult period and between the moult and subsequent breeding period. Clutch initiation date was found to be highly consistent in individual southern rockhopper penguins, but not affected by individual prebreeding foraging ranges revealing a likely individual trait (Dehnhard et al. 2015b, 2016; Morrison et al. 2016). Other parameters, such as sex, age or individual quality, could influence the date of return to the colony to breed (Thiebot et al. 2014b). Unfortunately, the information on breeding success at the individual level was missing in our study and did not permit to explore the relationships between body condition, timing of arrival and breeding success.

\section{Body condition and climate factors}

The body condition of males and females was impacted by all the climate factors considered, while there was no effect on breeding success. This could indicate that body condition has been kept above a certain threshold where it did not impact breeding success or that the extreme impact of diverse causes (i.e. weather, predation and/or pathogens) was overlying any trends. In the closely related southern rockhopper penguin, the body mass was evidenced to be affected by climate variables (Dehnhard et al. 2015a). We evidenced complex relationships between the body condition of individuals and the climatic conditions preceding the breeding season. The body condition of females during the breeding period was non-linearly related to the remote environmental variables (except for SIOD). Overall, females were in better body condition for negative values of SIOD and SSTa, although their body condition seemed to increase for positive SSTa. The body condition of males exhibited similar but less complex and more significant patterns, with decreasing body condition for increasing SAM, SIOD and SSTa but with slight increases in body condition for positive values of SAM. Positive values of SAM in South Atlantic Ocean 
(i.e. lower SST and stronger westerly winds) were found to increase body mass in the southern rockhopper penguin (Dehnhard et al. 2015a). Nevertheless, inter-annual variation in body mass should vary among studied populations (Dehnhard et al. 2013a; Crawford et al. 2006, 2008) reflecting possible regional differences in the environmental conditions. Similarly, the SAM-associated climatic conditions have already previously been associated with better foraging conditions and higher survival rates (southern rockhopper penguin; Dehnhard et al. 2011, 2013a, b). The SAM was also best explanatory factor for clutch initiation date in rockhopper penguins (i.e. earlier under positive SAM; Dehnhard et al. 2015b). Furthermore, Dehnhard et al. (2015b) demonstrated that heavier females producing heavier clutches and laid heavier eggs under lower SST. Finally, larger chicks at fledging positively correlated to higher provisioning rate by parents have greater likelihood of surviving to recruit into the population (Morrison et al. 2016; Horswill et al. 2014, 2017).

The area around Amsterdam Island presents characteristics of a subtropical gyre, i.e. quiescent conditions with little mixing from winds and occasional occurrence of mesoscale eddies leading to generally oligotrophic conditions. However, medium levels of production at the surface indicate a transition area between the Southern ocean and subtropical gyre (Visser et al. 2015). The subtropical gyre is characterized by globally low productivity due to weak mixing and mesoscale eddy activity as reported by satellite data (Antoine et al. 1996), oceanographic models (Machu et al. 2005), and in situ sampling (Visser et al. 2015).

In the Amsterdam Island area, positive SAM and SIOD correspond, respectively, to less wind at mid-latitude and warmer surface water (Lovenduski and Gruber 2005). Favourable oceanographic conditions would be generated by negative phases of both SIOD and SAM during pre-breeding while positive phases of these climate indices would correspond to beneficial conditions during pre-moult. These statements are supported by the relationships obtained between SSTa and body condition. Colder surface waters and strong wind during the austral winter period resulted in weak stratification and enhanced mixing of the water column (Fig. 6a, favourable conditions on the left panel vs unfavourable conditions on the right panel). These environmental conditions potentially injected deeper waters enriched in nutrients to refuel the biological production in the surface layer. The new biological production may sustain high prey abundance, which is an important process in the oligotrophic subtropical context. Nonetheless, it will take a considerable amount of time from increased nutrients over primary productivity to generate prey for penguins. Colder surface waters and increased wind could also directly affect the distribution of prey swarms and therefore foraging success (Dehnhard et al. 2013a). During the succeeding austral summer period and

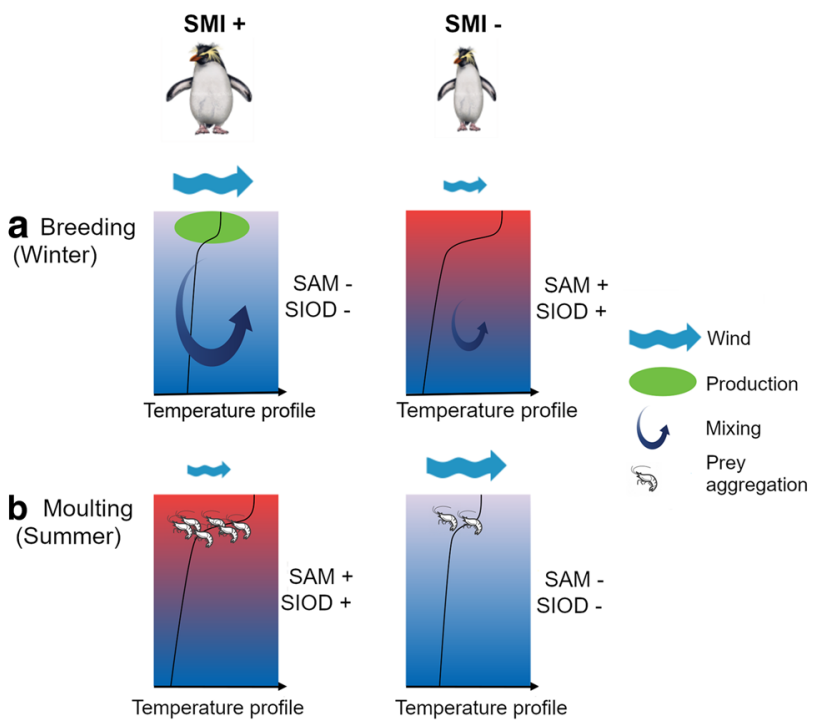

Fig. 6 Schematic effects of climatic factors [Southern Annular Mode (SAM) and Subtropical Indian Ocean Dipole (SIOD)] and the derived physical (wind and mixing) and trophic (primary production and prey densities) conditions during pre-breeding and pre-moult periods on body condition in adult northern rockhopper penguin on Amsterdam Island from 1994 to 2016 during a breeding and b moulting stages. Favourable conditions for body condition on the left panels versus unfavourable conditions on the right panels. The black line illustrates a typical temperature profile in the subtropical domain depicting either a weak or a strong stratification. Symbols $( \pm)$ represent, respectively, positive and negative SAM and SIOD

its associated bloom, warm surface waters induced stratified water column. The seasonal biological production accumulates at the thermocline and, as a result, mid-trophic levels are attracted by this vertical aggregation of biological production. Such oceanographic features may create favourable conditions for prey concentrations available at the depth of the thermocline for diving predators, such as penguins (Pelletier et al. 2012; Van Eeden et al. 2016). During the austral summer, a high stratification of the water column required for the bloom was maintained by weak winds conditions and, as a result, for the accumulation of biological production at the bottom of the surface layer (Fig. 6b). These climatic and oceanographic processes operating during the austral summer may explain the different (and nearly opposite) patterns which were observed during the pre-moult period compared to the pre-breeding period. During moulting, females and males had maximum body condition for intermediate values of SAM, and their body condition increased with increasing values of SIOD during the austral summer. The premoulting months are a key period for individuals that need to replenish their energetics reserves through a period of hyperphagia at sea (Thiebot et al. 2014a) before initiating their moult. We do not know where the individuals forage in the months during this particular period but we can hypothesize that females and males behaved similarly or at least 
they forage in areas similarly influenced by climatic factors. Nevertheless, the correlation maps allowed investigating spatial associations between body condition and SSTa patterns without a selection of a priori climate indices. Spatial patterns of correlation are similar for males and females, but more significant for males during the two periods (see Fig. 5). Here, this approach supports the robustness of the GAM analysis which provides congruent results. Despite the exploratory nature of this correlation analysis, such methods have also been proven to be useful in discovering new climate teleconnections (Von Storch and Zwiers 2001) and can be useful here to generate hypotheses on the potential foraging areas and to suggest other important remote climate forcing phenomena on penguins' body conditions (e.g. El Niño-Southern oscillation (ENSO)).

For northern rockhopper penguins, we found that individuals on average were in better condition during the moulting period compared to the breeding period, suggesting that body condition was probably fully restored during the premoulting months but not during the pre-breeding months (i.e., austral winter period previous to the onset of breeding). Birds used considerable reserves of energy during moulting explaining why they need to be in better condition before this stage. This dissimilarity in condition can also mirror the different seasonal availability of trophic resources or might indicate different foraging areas. Indeed Eudyptes penguins tended to exhibit large-scale dispersal during the pre-moult period (Lowther et al. 2014; Thiebot et al. 2014a; Horswill 2015; Whitehead et al. 2016).

Our results, showing no long-term trend in northern rockhopper penguin adult body condition at two critical periods of the life cycle, concurrent with changes in climate variables, combined with the synchronous dramatic long-term decline in breeding success and its lack of association with climatic factors, suggest that the causes of the long-term decline of the Amsterdam Island population does not originate solely from bottom-up effects linked to changing marine environment, at least during the pre-breeding and pre-moulting periods. Population declines should be due to low breeding success as observed here, but also to low adult survival, and low survival of immatures between fledging and recruitment at the colony, but no information is available for these two last parameters. Pathogen outbreaks (avian cholera and erysipelas causative agents) were identified to threaten seabird species on Amsterdam Island (Jaeger et al. 2018). Nonetheless, the effects of these pathogens on northern rockhopper penguins remain to be quantified and the responsible mechanisms to be identified. Other potential land-based factors are top-down effects due to predation pressure and/or harassment level. Native brown skuas Catharacta antarctica lonnbergi, introduced invasive brown rats Rattus norvegicus or feral cats Felis catus are known to predate on similar sized penguins and on northern rockhopper penguins at Amsterdam Island (Berruti 1981; Hunter 1990; Simeone and Luna-Jorquera 2012; Authors, personal observation). Fur seals Arctocephalus spp. occasionally hunt and prey upon northern rockhopper penguins (Roux and Hes 1984) and may be an additional cause of the population decline (Guinard et al. 1998). However, although the number of sub-Antarctic fur seals A. tropicalis at Amsterdam Island increased dramatically between the 1970s and late 1990s, it has stabilized since the mid-2000s (Pacoureau et al. 2017).

\section{Conclusion}

In conclusion, we suspect that northern rockhopper penguin population decline at Amsterdam Island might result from effects of top-down pressure (i.e. on land threats: predation or harassment), disease, and bottom-up environmental forces (i.e. food resources) (Regehr and Montevecchi 1997; Horswill et al. 2016), which may act individually or more likely in combination. Further information on the drivers of the population decline and particularly the low breeding success is needed. Additional field and modelling studies are needed to understand and estimate the effects of potential disease outbreaks and predators on the demography and population dynamics of northern rockhopper penguins, which will help designing management plans aiming at conserving this endangered species.

Supplementary Information The online version contains supplementary material available at https://doi.org/10.1007/s00227-021-03832-z.

Acknowledgements We thank D. Joubert for data management, M Quintin for data preparation, and Y Tremblay, JY Georges, L Zimmerman, G Beauplet, M Ghestem, T. Deville, F Le Bouard, P Thyrland, M Authier; JB Thiebot, N Mignot, C Alotto, C Chauvel, L Gaillard, B Callard, J Demay, R Bigonneau, R Bazire, H Le Berre, M Quintin for their contribution to the long-term monitoring. The long-term study was supported financially and logistically by the French Polar Institute IPEV (program 109, resp. H. Weimerskirch) and the Zone Atelier Antarctique ZATA CNRS-INEE. We would further like to thank Nina Dehnhard and an anonymous reviewer and the associated editor Thomas A Clay for helpful comments on manuscript.

Author contributions Study design: $\mathrm{CB}, \mathrm{KD}, \mathrm{HW}$. Data analysis and processing: KD, CB, CC, PT. Funding acquisition: HW. KD wrote the text and all authors edited and revised the manuscript, gave final approval for publication and agreed to be held accountable for the content therein.

Funding The long-term study was supported financially and logistically by the French Polar Institute IPEV (program 109, resp. H. Weimerskirch) and the Zone Atelier Antarctique ZATA CNRS-INEE and Terres Australes et Antarctiques Françaises.

Availability of data and material The data used in the present article will be provided for open access as supplementary. 
Code availability The custom code used in the present article will be provided for open access as supplementary.

\section{Compliance with ethical standards}

Conflicts of interest The authors declare that they have no conflicts of interest.

Ethics approval The Ethics Committee of IPEV and the Comité Environnement Polaire approved the field procedures for the French Southern Territories.

Consent to participate All authors have agreed to participate in the study and its writing in the form of an article.

Consent for publication All authors have given their consent for the article to be submitted to Marine Biology.

\section{References}

Adams N, Brown C (1990) Energetics of molt in penguins. Academic Press, New York, pp 297-315

Altmann J, Alberts SC (2005) Growth rates in a wild primate population: ecological influences and maternal effects. Behav Ecol Sociobiol 57:490-501

Antoine D, André J, Morel A (1996) Oceanic primary production: 2. Estimation at global scale from satellite (coastal zone color scanner) chlorophyll. Glob Biogeochem Cycles 10:57-69

Badyaev AV (2002) Growing apart: an ontogenetic perspective on the evolution of sexual size dimorphism. Trends Ecol Evol $17: 369-378$

Barbraud C, Rolland V, Jenouvrier S, Nevoux M, Delord K, Weimerskirch H (2012) Effects of climate change and fisheries bycatch on Southern Ocean seabirds: a review. Mar Ecol Prog Ser 454:285-307

Barbraud C, Delord K, Bost C, Chaigne A, Marteau C, Weimerskirch $\mathrm{H}$ (2020) Population trends of penguins in the French Southern Territories. Polar Biol 43:835-850. https://doi.org/10.1007/s0030 0-020-02691-6

Barlow KE, Boyd IL, Croxall JP, Reid K, Staniland IJ, Brierley AS (2002) Are penguins and seals in competition for Antarctic krill at South Georgia? Mar Biol 140:205-213. https://doi. org/10.1007/s00227-001-0691-7

Behera SK, Yamagata T (2001) Subtropical SST dipole events in the southern Indian Ocean. Geophys Res Lett 28:327-330

Behrenfeld MJ, O'Malley RT, Siegel DA, McClain CR, Sarmiento JL, Feldman GC, Milligan AJ, Falkowski PG, Letelier RM, Boss ES (2006) Climate-driven trends in contemporary ocean productivity. Nature 444:752-755. https://doi.org/10.1038/nature05317

Berruti A (1981) The status of the royal penguin and fairy prion at Marion Island, with notes on feral cat predation on nestlings of large birds. Cormorant 9:123-127

BirdLife International (2018). Northern Rockhopper Pengui . Eudyptes moseleyi. The IUCN Red List of Threatened Species 2018: e.T22734408A132664126. https://doi.org/10.2305/IUCN. UK.2018-2.RLTS.T22734408A132664126.en

Boersma PD (2008) Penguins as marine sentinels. Bioscience 58:597-607

Borboroglu PG, Boersma PD (2013) Penguins: natural history and conservation. University of Washington Press, Seattle

Bost CA, Cotté C, Terray P, Barbraud C, Bon C, Delord K, Gimenez O, Handrich Y, Naito Y, Guinet C (2015) Large-scale climatic anomalies affect marine predator foraging behaviour and demography. Nat Commun 6:1-9

Boutin S, Larsen KW (1993) Does food availability affect growth and survival of males and females differently in a promiscuous small mammal, Tamiasciurus hudsonicus? J Anim Ecol 62:364-370

Burnham KP, Anderson DR (2002) Model selection and multimodel inference: a practical information-theoretic approach. Springer, New York

Cabré A, Marinov I, Leung S (2015) Consistent global responses of marine ecosystems to future climate change across the IPCC AR5 earth system models. Clim Dyn 45:1253-1280

Carneiro APB, Manica A, Clay TA, Silk JRD, King M, Phillips RA (2016) Consistency in migration strategies and habitat preferences of brown skuas over two winters, a decade apart. Mar Ecol Prog Ser 553:267-281

Cherel Y, Robin J-P, Walch O, Karmann H, Netchitailo P, Le Maho Y (1988a) Fasting in king penguin. I. Hormonal and metabolic changes during breeding. Am J Physiol Regul Integr Comp Physiol 254:R170-R177

Cherel Y, Leloup J, Le Maho Y (1988b) Fasting in king penguin. II. Hormonal and metabolic changes during molt. Am J Physiol Regul Integr Comp Physiol 254:R178-R184

Cherel Y, Tremblay Y, Guinard E, Georges J-Y (1999) Diving behaviour of female northern rockhopper penguins, Eudyptes chrysocome moseleyi, during the brooding period at Amsterdam Island (Southern Indian Ocean). Mar Biol 134:375-385

Cooper J, Crawford RJ, De Villiers MS, Dyer BM, Hofmeyr GG, Jonker A (2009) Disease outbreaks among penguins at subAntarctic Marion Island: a conservation concern. Mar Ornithol 37:193-196

Crawford RJM, Dyer BM, Cooper J, Underhill LG (2006) Breeding numbers and success of Eudyptes penguins at Marion Island, and the influence of mass and time of arrival of adults. CCAMLR Sci 13:175-190

Crawford R, Makhado A, Upfold L, Dyer B (2008) Mass on arrival of rockhopper penguins at Marion Island correlated with breeding success. Afr J Mar Sci 30:185-188

Crawford RJ, Whittington P, Upfold L, Ryan P, Petersen S, Dyer B, Cooper J (2009) Recent trends in numbers of four species of penguins at the Prince Edward Islands. Afr J Mar Sci 31:419-426

Crossin GT, Trathan PN, Phillips RA, Dawson A, Le Bouard F, Williams TD (2010) A carryover effect of migration underlies individual variation in reproductive readiness and extreme egg size dimorphism in macaroni penguins. Am Nat 176:357-366

Croxall J, Lishman G (1987) The food and feeding ecology of penguins. Cambridge University Press, Cambridge, pp 101-133

Cuthbert R, Cooper J, Burle M-H, Glass CJ, Glass JP, Glass S, Glass T, Hilton GM, Sommer ES, Wanless RM (2009) Population trends and conservation status of the Northern Rockhopper Penguin Eudyptes moseleyi at Tristan da Cunha and Gough Island. Bird Conserv Int 19:109-120

Cuthbert RJ (2013) Northern rockhopper penguin (Eudyptes moseleyi). Penguins. Natural history and conservation. University of Washington Press, Seattle, WA, 131-143

De Lisle G, Stanislawek W, Moors P (1990) Pasteurella multocida infections in rockhopper penguins (Eudyptes chrysocome) from Campbell Island, New Zealand. J Wildl Dis 26:283-285

Dehnhard N, Voigt CC, Poisbleau M, Demongin L, Quillfeldt P (2011) Stable isotopes in southern rockhopper penguins: foraging areas and sexual differences in the non-breeding period. Polar Biol 34:1763-1773

Dehnhard N, Ludynia K, Poisbleau M, Demongin L, Quillfeldt P (2013a) Good Days, bad days: wind as a driver of foraging success in a flightless seabird, the Southern Rockhopper 
penguin. PLoS ONE 8:e79487. https://doi.org/10.1371/journ al.pone.0079487

Dehnhard N, Poisbleau M, Demongin L, Ludynia K, Lecoq M, Masello JF, Quillfeldt P (2013b) Survival of rockhopper penguins in times of global climate change. Aquat Conserv Mar Freshw Ecosyst 23:777-789. https://doi.org/10.1002/aqc.2331

Dehnhard N, Eens M, Demongin L, Quillfeldt P, Poisbleau M (2015a) Individual consistency and phenotypic plasticity in rockhopper penguins: female but not male body mass links environmental conditions to reproductive investment. PLoS ONE 10:e0128776

Dehnhard N, Eens M, Demongin L, Quillfeldt P, Suri D, Poisbleau M (2015b) Limited individual phenotypic plasticity in the timing of and investment into egg laying in southern rockhopper penguins under climate change. Mar Ecol Prog Ser 524:269-281. https:// doi.org/10.3354/meps11154

Dehnhard N, Eens M, Sturaro N, Lepoint G, Demongin L, Quillfeldt P, Poisbleau M (2016) Is individual consistency in body mass and reproductive decisions linked to individual specialization in foraging behavior in a long-lived seabird? Ecol Evol 6:4488-4501. https://doi.org/10.1002/ece3.2213

Demongin L, Poisbleau M, Strange IJ, Quillfeldt P (2010) Effects of severe rains on the mortality of southern rockhopper penguin (Eudyptes chrysocome) chicks and its impact on breeding success. Ornitol Neotropical 21:439-443

Dias MP, Martin R, Pearmain EJ, Burfield IJ, Small C, Phillips RA, Yates O, Lascelles B, Borboroglu PG, Croxall JP (2019) Threats to seabirds: a global assessment. Biol Conserv 237:525-537

Drent R, Daan S (1980) the prudent parent: energetic adjustements in avian breeding. Ardea 68:225-252

Duroselle T, Tollu B (1977) Manifestations sonores des sphéniscidés du genre Eudyptes dans les îles Australes Françaises

Gong D, Wang S (1999) Definition of Antarctic oscillation index. Geophys Res Lett 26:459-462

Goodman D (1974) Natural selection and a cost ceiling on reproductive effort. Am Nat 108:247-268

Graham RM, De Boer AM (2013) The dynamical subtropical front. J Geophys Res Oceans 118:5676-5685

Guinard E, Weimerskirch H, Jouventin P (1998) Population changes and demography of the Northern Rockhopper Penguin on Amsterdam and Saint Paul islands. Colon Waterbirds 21:222-228

Guinet C, Cherel Y, Ridoux V, Jouventin P (1996) Consumption of marine resources by seabirds and seals in Crozet and Kerguelen waters: changes in relation to consumer biomass 1962-65. Antarct Sci 8:23-30

Hall A, Visbeck M (2002) Synchronous variability in the Southern Hemisphere atmosphere, sea ice, and ocean resulting from the annular mode. J Clim 15:3043-3057

Heerah K, Dias M, Delord K, Oppel S, Barbraud C, Weimerskirch H, Bost C (2019) Important areas and conservation sites for a community of globally threatened marine predators of the Southern Indian Ocean. Biol Conserv 234:192-201

Hermes J, Reason C (2005) Ocean model diagnosis of interannual coevolving SST variability in the South Indian and South Atlantic Oceans. J Clim 18:2864-2882

Hilton GM, Thompson DR, Sagar PM, Cuthbert RJ, Cherel Y, Bury SJ (2006) A stable isotopic investigation into the causes of decline in a sub-Antarctic predator, the rockhopper penguin Eudyptes chrysocome. Glob Change Biol 12:611-625

Hiscock JA, Chilvers BL (2014) Declining eastern rockhopper (Eudyptes filholi) and erect-crested (E. sclateri) penguins on the Antipodes Islands. N Z J Ecol 38:124-131

Horswill C (2015) The relative importance of opposing drivers in determining population change in macaroni penguins Eudyptes chrysolophus (Unpublished Doctoral dissertation, University of Glasgow)
Horswill C, Matthiopoulos J, Green JA, Meredith MP, Forcada J, Peat H, Preston M, Trathan PN, Ratcliffe N (2014) Survival in macaroni penguins and the relative importance of different drivers: individual traits, predation pressure and environmental variability. J Anim Ecol 83:1057-1067. https://doi. org/10.1111/1365-2656.12229

Horswill C, Matthiopoulos J, Ratcliffe N, Green JA, Trathan PN, McGill RAR, Phillips RA, O'Connell TC (2016) Drivers of intrapopulation variation in resource use in a generalist predator, the macaroni penguin. Mar Ecol Prog Ser 548:233-247. https://doi. org/10.3354/meps 11626

Horswill C, Trathan PN, Ratcliffe N (2017) Linking extreme interannual changes in prey availabiity to for aging behaviour and breeding investment in a marine predator, the macaroni penguin. Plos one 12(9):e0184114

Hunter S (1990) The impact of introduced cats on the predator-prey interactions of a sub-Antarctic avian community. Antarctic ecosystems. Springer, New York, pp 365-371

Iles DT, Lynch H, Ji R, Barbraud C, Delord K, Jenouvrier S (2020) Sea ice predicts long-term trends in Adélie penguin population growth, but not annual fluctuations: Results from a range-wide multiscale analysis. Glob Change Biol. https://doi.org/10.1111/ gcb. 15085

Jaeger A, Lebarbenchon C, Bourret V, Bastien M, Lagadec E, Thiebot J-B, Boulinier T, Delord K, Barbraud C, Marteau C, Dellagi K, Tortosa P, Weimerskirch H (2018) Avian cholera outbreaks threaten seabird species on Amsterdam Island. PLoS ONE 13:e0197291. https://doi.org/10.1371/journal.pone.0197291

Kitaysky A, Wingfield J, Piatt JF (1999) Dynamics of food availability, body condition and physiological stress response in breeding black-legged kittiwakes. Funct Ecol 13:577-584

Le Bohec C, Durant JM, Gauthier-Clerc M, Stenseth NC, Park YH, Pradel R, Grémillet D, Gendner J-P, Le Maho Y (2008) King penguin population threatened by Southern Ocean warming. Proc Natl Acad Sci USA 105:2493-2497

Lovenduski NS, Gruber N (2005) Impact of the Southern Annular Mode on Southern Ocean circulation and biology. Geophys Res Lett 32:L11603

Lowther AD, Lydersen C, Biuw M, de Bruyn PN, Hofmeyr GJ, Kovacs KM (2014) Post-breeding at-sea movements of three centralplace foragers in relation to submesoscale fronts in the Southern Ocean around Bouvetøya. Antarct Sci 26:533-544

Machu E, Biastoch A, Oschlies A, Kawamiya M, Lutjeharms J, Garcon V (2005) Phytoplankton distribution in the Agulhas system from a coupled physical-biological model. Deep Sea Res Part Oceanogr Res Pap 52:1300-1318

Marshall GJ (2003) Trends in the Southern Annular Mode from observations and reanalyses. J Clim 16:4134-4143

Meijer T, Drent R (1999) Re-examination of the capital and income dichotomy in breeding birds. Ibis 141:399-414

Moline MA, Claustre H, Frazer TK, Schofield O, Vernet M (2004) Alteration of the food web along the Antarctic Peninsula in response to a regional warming trend. Glob Change Biol 10:1973-1980

Morrison KW, Battley PF, Sagar PM, Thompson DR (2015) Population dynamics of Eastern Rockhopper Penguins on Campbell Island in relation to sea surface temperature 1942-2012: current warming hiatus pauses a long-term decline. Polar Biol 38:163-177. https ://doi.org/10.1007/s00300-014-1575-x

Morrison KW, Morrison NC, Buchheit RM, Dunn R, Battley PF, Thompson DR (2016) The canalized parental roles of a Eudyptes penguin constrain provisioning and growth of chicks during nutritional stress. Behav Ecol Sociobiol 70:467-479

Oro D, Furness RW (2002) Influences of food availability and predation on survival of kittiwakes. Ecology 83:2516-2528 
Pacoureau N, Authier M, Delord K, Guinet C, Barbraud C (2017) Early-life density-dependence effects on growth and survival in subantarctic fur seals. Popul Ecol 59:139-155

Parmesan C, Yohe G (2003) A globally coherent fingerprint of climate change impacts across natural systems. Nature 421:37-42

Peig J, Green AJ (2009) New perspectives for estimating body condition from mass/length data: the scaled mass index as an alternative method. Oikos 118:1883-1891. https://doi.org/10.111 1/j.1600-0706.2009.17643.x

Pelletier L, Kato A, Chiaradia A, Ropert-Coudert Y (2012) Can thermoclines be a cue to prey distribution for marine top predators? A case study with little penguins. PLoS ONE 7:e31768

Radchuk V, Reed T, Teplitsky C, Van De Pol M, Charmantier A, Hassall C, Adamík P, Adriaensen F, Ahola MP, Arcese P (2019) Adaptive responses of animals to climate change are most likely insufficient. Nat Commun 10:1-14

Regehr H, Montevecchi W (1997) Interactive effects of food shortage and predation on breeding failure of black-legged kittiwakes: indirect effects of fisheries activities and implications for indicator species. Mar Ecol Prog Ser 155:249-260

Robinson S, Chiaradia A, Hindell MA (2005) The effect of body condition on the timing and success of breeding in Little Penguins Eudyptula minor. Ibis 147:483-489

Roux J, Hes A (1984) The seasonal haul-out cycle of the fur seal Arctocephalus tropicalis (Gray, 1872) on Amsterdam Island. Mammalia 48:377-389

Salton M, Saraux C, Dann P, Chiaradia A (2015) Carry-over body mass effect from winter to breeding in a resident seabird, the little penguin. R Soc Open Sci 2:140390

Simeone A, Luna-Jorquera G (2012) Estimating rat predation on Humboldt Penguin colonies in north-central Chile. J Ornithol 153:1079-1085

Stearns S (1976) Life-history tactics: a review of the ideas. Q Rev Biol 51:3-47

Steinfurth A, Booth JM, White J, Bond AL, McQuaid CD (2019) Sexual and geographic dimorphism in northern rockhopper penguins breeding in the South Atlantic Ocean. Endanger Species Res 39:293-302

Team RC (2019) R: A Language and Environment for Statistical Computing (Version 3.5. 2, R Foundation for Statistical Computing, Vienna, Austria, 2018)

Terray P (2011) Southern Hemisphere extra-tropical forcing: a new paradigm for El Niño-Southern Oscillation. Clim Dyn 36:2171-2199

Thiebot J-B, Cherel Y, Trathan PN, Bost C-A (2012) Coexistence of oceanic predators on wintering areas explained by populationscale foraging segregation in space or time. Ecology 93:122-130

Thiebot J, Cherel Y, Acqueberge M, Prudor A, Trathan PN, Bost C (2014a) Adjustment of pre-moult foraging strategies in Macaroni Penguins Eudyptes chrysolophus according to locality, sex and breeding status. Ibis 156:511-522

Thiebot J, Authier M, Trathan P, Bost C (2014b) Gentlemen first? "Broken stick" modelling reveals sex-related homing decision date in migrating seabirds. J Zool 292:25-30

Thompson DW, Solomon S, Kushner PJ, England MH, Grise KM, Karoly DJ (2011) Signatures of the Antarctic ozone hole in
Southern Hemisphere surface climate change. Nat Geosci 4:741-749

Tollu B (1978) Les manchots. La Recherche 93:834-844

Trathan PN, García-Borboroglu P, Boersma D, Bost C, Crawford RJ, Crossin GT, Cuthbert RJ, Dann P, Davis LS, De La Puente S (2015) Pollution, habitat loss, fishing, and climate change as critical threats to penguins. Conserv Biol 29:31-41

Tremblay Y, Cherel Y (2003) Geographic variation in the foraging behaviour, diet and chick growth of rockhopper penguins. Mar Ecol Prog Ser 251:279-297

Tremblay Y, Guinard E, Cherel Y (1997) Maximum diving depths of northern rockhopper penguins (Eudyptes chrysocome moseleyi) at Amsterdam Island. Polar Biol 17:119-122

Van Eeden R, Reid T, Ryan PG, Pichegru L (2016) Fine-scale foraging cues for African penguins in a highly variable marine environment. Mar Ecol Prog Ser 543:257-271

Visser AW, Nielsen TG, Middelboe M, Høyer JL, Markager S (2015) Oceanography and the base of the pelagic food web in the southern Indian Ocean. J Plankton Res 37:571-583

Von Storch H, Zwiers FW (2001) Statistical analysis in climate research. Cambridge University Press, Cambridge, p 484 (ISBN 0521450713)

Warham J (1970) Breeding seasons and sexual dimorphism in Rockhopper penguins. Auk 89:86-105

Weimerskirch H, Louzao M, de Grissac S, Delord K (2012) Changes in wind pattern alter albatross distribution and life-history traits. Science 335:211-214

Whitehead T, Kato A, Ropert-Coudert Y, Ryan PG (2016) Habitat use and diving behaviour of macaroni Eudyptes chrysolophus and eastern rockhopper E. chrysocomefilholi penguins during the critical pre-moult period. Mar Biol 163:19

Wikelski M, Wrege PH (2000) Niche expansion, body size, and survival in Galápagos marine iguanas. Oecologia 124:107-115

Williams T (1995) The penguins. Bird families of the world. Oxford University Press, Oxford

Wolfaardt AC, Crofts S, Baylis AM (2012) Effects of a storm on colonies of seabirds breeding at the Falkland Islands. Mar Ornithol 40:129-133

Wood S (2004) Stable and efficient multiple smoothing parameter estimation for generalized additive models. J Am Stat Assoc 99:673-686

Wood S (2017) Generalized additive models: an introduction with R, 2nd edn. Chapman and Hall, Boca Raton

Wood S, Scheipl F, Wood MS (2017) Package "gamm4." Am Stat 45:339

Zuur A, Ieno EN, Walker N, Saveliev AA, Smith GM (2009) Mixed effects models and extensions in ecology with R. Springer, New York

Publisher's Note Springer Nature remains neutral with regard to jurisdictional claims in published maps and institutional affiliations. 


\section{Terms and Conditions}

Springer Nature journal content, brought to you courtesy of Springer Nature Customer Service Center GmbH ("Springer Nature").

Springer Nature supports a reasonable amount of sharing of research papers by authors, subscribers and authorised users ("Users"), for smallscale personal, non-commercial use provided that all copyright, trade and service marks and other proprietary notices are maintained. By accessing, sharing, receiving or otherwise using the Springer Nature journal content you agree to these terms of use ("Terms"). For these purposes, Springer Nature considers academic use (by researchers and students) to be non-commercial.

These Terms are supplementary and will apply in addition to any applicable website terms and conditions, a relevant site licence or a personal subscription. These Terms will prevail over any conflict or ambiguity with regards to the relevant terms, a site licence or a personal subscription (to the extent of the conflict or ambiguity only). For Creative Commons-licensed articles, the terms of the Creative Commons license used will apply.

We collect and use personal data to provide access to the Springer Nature journal content. We may also use these personal data internally within ResearchGate and Springer Nature and as agreed share it, in an anonymised way, for purposes of tracking, analysis and reporting. We will not otherwise disclose your personal data outside the ResearchGate or the Springer Nature group of companies unless we have your permission as detailed in the Privacy Policy.

While Users may use the Springer Nature journal content for small scale, personal non-commercial use, it is important to note that Users may not:

1. use such content for the purpose of providing other users with access on a regular or large scale basis or as a means to circumvent access control;

2. use such content where to do so would be considered a criminal or statutory offence in any jurisdiction, or gives rise to civil liability, or is otherwise unlawful;

3. falsely or misleadingly imply or suggest endorsement, approval, sponsorship, or association unless explicitly agreed to by Springer Nature in writing;

4. use bots or other automated methods to access the content or redirect messages

5. override any security feature or exclusionary protocol; or

6. share the content in order to create substitute for Springer Nature products or services or a systematic database of Springer Nature journal content.

In line with the restriction against commercial use, Springer Nature does not permit the creation of a product or service that creates revenue, royalties, rent or income from our content or its inclusion as part of a paid for service or for other commercial gain. Springer Nature journal content cannot be used for inter-library loans and librarians may not upload Springer Nature journal content on a large scale into their, or any other, institutional repository.

These terms of use are reviewed regularly and may be amended at any time. Springer Nature is not obligated to publish any information or content on this website and may remove it or features or functionality at our sole discretion, at any time with or without notice. Springer Nature may revoke this licence to you at any time and remove access to any copies of the Springer Nature journal content which have been saved.

To the fullest extent permitted by law, Springer Nature makes no warranties, representations or guarantees to Users, either express or implied with respect to the Springer nature journal content and all parties disclaim and waive any implied warranties or warranties imposed by law, including merchantability or fitness for any particular purpose.

Please note that these rights do not automatically extend to content, data or other material published by Springer Nature that may be licensed from third parties.

If you would like to use or distribute our Springer Nature journal content to a wider audience or on a regular basis or in any other manner not expressly permitted by these Terms, please contact Springer Nature at

onlineservice@springernature.com 